\title{
HEURÍSTICA PARA A COMPOSIÇÃO DE REFERENCIAL TEÓRICO
}

\section{HEURISTIC METHOD FOR COMPOSING A LITERATURE REVIEW}

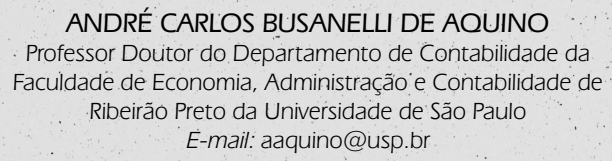

Professor Doutor do Departamento de Contabilidạde da Faculdade de Economia, Administração e Contabilidade de Ribeirão Preto da Universidade de São Paulo E-mail: aaquino@usp.br

MARCELO SANCHES PAGLIARUSS

Professor Assistente da Fucape Business School E-mail:marcelo@fucape.br

EUGÊNIO JOSÉ SILVA BITTI

Mestre em Ciências Contábeis pela Fucape Business School

E-mail: ejsbitti@uol.com.br

\section{RESUMO}

O processo de fazer e documentar um referencial teórico é usualmente idiossincrático. Luft e Shields (2003) apresentaram um processo de mapeamento da pesquisa empírica em contabilidade gerencial. Propõe-se um método heurístico formal para o processo de elaboração do referencial teórico que complementa o processo de mapeamento proposto por Luft e Shields (2003). A heurística apresentada, aqui, é baseada no conceito de camadas e visa à redução dos erros de inclusão e exclusão que podem ocorrer durante a seleção de estudos anteriores. Esses erros impactam na validade interna e na validade do construto, já que o referencial teórico suporta a operacionalização das variáveis, as escolhas das proxies e a seleção dos métodos. É apresentado um exemplo real da aplicação da heurística na condução de uma Dissertação de Mestrado em Ciências Contábeis. Conclui-se que a aplicação da heurística permite ao pesquisador identificar os autores de destaque no tópico de pesquisa escolhido, a aceitação da comunidade científica com relação a uma ou outra corrente teórica no que diz respeito à explicação do fenômeno, além das teorias mais utilizadas em uma área de conhecimento. Por meio dessa heurística, a operacionalização do estudo exemplificado identificou nos estudos empíricos anteriores, 199 proxies ao longo de 58 variáveis relacionadas, 8 diferentes teorias, 57 autores, possibilitando um mapeamento do tema com uso de critérios mais objetivos de revisão.

Palavras chave: Referencial teórico. Validade interna. Validade de construto. Processo heurístico. Contabilidade gerencial.

\section{ABSTRACT}

The process of doing and documenting a literature review is usually quite idiosyncratic, Luft and Shields (2003) presented a process to map theory-consistent empirical research in management accounting. We propose a formal heuristic method for the process of literature reviewing that integrates their mapping process. The heuristic presented here is based on the concept of layers, and it is aimed at mitigating inclusion errors and exclusion errors which might occur when selecting papers for a literature review. These errors impact internal validity and construct validity, since a literature review defines operationalization of variables, choices of proxies and selection of methods. We present an example of actual utilization of the process in a dissertation conducted in a Master's Program in Accountancy. We conclude that the heuristics allowed the researcher to identify outstanding authors in the chosen topic, and the main theories used to support empirical studies. The heuristics supported the operationalization of a research by means of an identification of 199 proxies for 58 related variables, eight theoretical approaches and 57 authors. These results were used to draw a map of the selected topic, based on more objective criteria.

Keywords: Literature review. Internal validity. Construct validity. Heuristic process: Management accounting. 


\section{INTRODUC̣ÃO}

A contabilidade gerencial engloba um amplo conjunto de práticas e técnicas, resultando em um complexo campo de pesquisa. Como os aspectos práticos constituem questões centrais no estudo da contabilidade gerencial, a pesquisa, nesse campo, é dirigida tanto para avaliar e desenvolver a prática como para gerar conhecimento científico. Bruns e Kaplan (1987) sugerem que Contabilidade Gerencial cria informação dentro da organização para facilitar os processos de decisão e controle gerenciais. De fato, observa-se que o conhecimento produzido pela pesquisa, nessa área, muitas vezes objetiva dar suporte à tomada de decisão. A pesquisa voltada para 0 suporte à tomada de decisão ou pragmática, (ABBOTT, 2004, p. 38), usualmente, emprega estratégias de pesquisa que visam a identificar relações de causa e efeito entre variáveis. Tais relações de causalidade são sugeridas e fundamentadas por meio de proposições teóricas gerais (SUTTON; STAW, 1995), as quais são interpretadas para a situação específica que envolve o objeto da pesquisa. É usual, na aplicação do método científico no contexto do programa pragmático, que o pesquisador identifique o estado da arte em relação a um tópico de pesquisa específico. Tal mapeamento do conhecimento científico existente envolve a identificação de estudos anteriores, teóricos e empíricos. Após essa identificação, espera-se que o pesquisador seja capaz de propor iniciativas originais de pesquisa, que avancem o conhecimento da área. Conseqüentemente, o desenho de uma pesquisa em andamento é diretamente afetado pelos trabalhos existentes revisados e as decisões relacionadas a esse desenho terão implicações no potencial da pesquisa em dar suporte à tomada de decisão (SCANDURA; WILLIAMS, 2000).

No presente trabalho, é proposta uma heurística visando a sistematizar a etapa de elaboração de referencial teórico, com o foco no suporte às escolhas operacionais da pesquisa em Contabilidade Gerencial. A proposta de heurística, aqui apresentada, parte dos procedimentos utilizados por Luft e Shields (2003) no mapeamento da pesquisa empírica em Contabilidade Gerencial. O processo de mapeamento oferecido por Luft e Shields (2003) foi realizado a partir de um conjunto de trabalhos empíricos selecionado em seis periódicos da área de Contabilidade. A heurística, proposta aqui, complementa os procedimentos de Luft e Shields (2003) ao definir um processo iterativo para a identificação de pesquisas anteriores relacionadas a um dado tópico de pesquisa. Propõem-se que o referencial teórico de um estudo deve ser avaliado de maneira semelhante à parte empírica do trabalho científico, pois tal revisão confere legitimidade à operacionalização da pesquisa empírica.

A contribuição esperada deste trabalho é o oferecimento de um procedimento de análise mais refinado em relação ao mapeamento de trabalhos empíricos apresentado por Luft e Shields (2003). O processo conduzido pelos referidos autores teve como objetivo apresentar uma visão geral da pesquisa em Contabilidade Gerencial, enquanto a heurística, aqui proposta, fornece subsídios para a apresentação de uma visão focada sobre um tópico específico da contabilidade gerencial. Entende-se que um processo heurístico iterativo é requerido para a elaboração do referencial teórico, especialmente na etapa de seleção de estudos anteriores. O processo pode ser resumidamente descrito como composto pelas etapas: construção da base de dados bibliográfica; mapeamento dos estudos existentes e escrita. Apresenta-se o processo no decorrer do texto e, em seguida, mostram-se os resultados da aplicação do processo na elaboração do referencial teórico da dissertação de mestrado de um dos co-autores. Procura-se destacar os detalhes do uso dos procedimentos propostos, com o objetivo de permitir a sua aplicação imediata pelos demais pesquisadores interessados. Uma discussão sobre os resultados de cada etapa proposta é oferecida, com destaque para a implicação dos resultados da heurística no desenho da pesquisa conduzida na dissertação.

\section{A PESOUISA EM CONTABILIDADE GERENCIAL E AS DIFICULDADES NA ELABORAÇÃO DO REFERENCIAL TEÓRICO}

Compor o referencial teórico de uma pesquisa em Contabilidade Gerencial é uma tarefa complexa. Devido à variedade de fenômenos e contextos, as pesquisas na área têm sido conduzidas por meio de abordagens teóricas originárias de diferentes áreas do conhecimento dentro das Ciências Sociais, com destaque para a Economia, a Psicologia e a Sociologia (LUFT; SHIELDS, 2002). Além de serem investigados com a ajuda de diferentes abordagens teóricas, os fenômenos que constituem a Contabilidade Gerencial não são unitários, tampouco homogêneos (HOPWOOD, 2002), além de estudados por meio de diferentes estratégias de pesquisa. Como resultado, as pesquisas, na área, têm sido conduzidas em uma perspectiva ampla, com maior pluralidade de métodos e formas de explicações do que a pesquisa em finanças, por exemplo. Essa amplitude de investigação traz maiores dificuldades ao pesquisador que deseja sintetizar estudos empíricos anteriores e consolidar seus achados em um dado tópico em Contabilidade Gerencial. Usualmente, é difícil obter uma interpretação geral, pois as teorias de áreas diferentes são fundamentadas em pressupostos diferentes e divergentes.

Não é surpreendente, então, que o referencial teórico de estudos conduzidos na área de Contabilidade Gerencial compartilhe muitas semelhanças com a pesquisa em Administração, também caracterizada pela pluralidade de objetos de estudos e estratégias de pesquisa. A forma de 
apresentação do referencial teórico em Administração tem sido criticada por caracterizar-se como uma narrativa que meramente descreve as contribuições feitas por estudos precedentes em um tópico específico de pesquisa (FINK, 1998; HART, 1998). Também são apontadas: a presença de viés de seleção (FINK, 1998; HART, 1998) e a falta de avaliação crítica ao incluir trabalhos no referencial teórico (TRANFIELD; DENYER; SMART, 2003).

Entende-se que o referencial teórico engloba uma fundamentação teórica e um conjunto de estudos empíricos anteriores no tópico de pesquisa. A fundamentação teórica fornece a sustentação para o estabelecimento das relações causais que irão guiar a pesquisa, para a seleção das fontes de dados, a forma dos modelos causais, a análise e a explicação. Apesar da falta do consenso sobre como definir uma teoria, há um sólido consenso sobre o uso de abordagens teóricas nas investigações científicas. Por exemplo, Sutton e Straw (1995) apresentam uma explanação detalhada do que não é uma teoria. Whetten (1989) sugere um conjunto de critérios que permitem a um pesquisador identificar, claramente, uma teoria ao se deparar com uma. E Martins (2005) discute aspectos de teorias e modelos em Ciências Contábeis. Em geral, espera-se que o pesquisador use o conjunto selecionado de estudos empíricos anteriores para avaliar o estado atual da aceitação das teorias utilizadas e para documentar os construtos e as proxies empregadas nas investigações. Além disso, os estudos empíricos anteriores podem revelar os resultados consistentes e as limitações dos trabalhos existentes, aspectos essenciais para avaliar a pertinência de um estudo em andamento e essencial aos mestrandos e doutorandos, os quais começam a construir expertise no tema.
No presente estudo, assume-se que é inviável atingir o melhor conjunto de estudos anteriores para a construção do referencial teórico de um trabalho em andamento. Argumenta-se, primeiramente, que, mesmo que o pesquisador tenha acesso a todos os principais periódicos pertinentes ao assunto da pesquisa, a própria definição dos principais periódicos é uma classificação subjetiva. Sendo assim, existe um viés intrínseco que afeta a seleção dos trabalhos. Em seguida, é possível que um importante trabalho empírico ou teórico fique ausente do conjunto selecionado, o que é muito provável se tal trabalho representar uma ruptura do pensamento dominante na pesquisa anterior no tema. Em terceiro lugar, é possível que um trabalho relevante não seja contemplado, pois não foi escrito em inglês ou porque não foi publicado, ainda, em um dos principais periódicos.

A heurística, aqui proposta, tem como objetivo contribuir para que o pesquisador alcance o melhor conjunto possível entre os diferentes conjuntos de estudos empíricos e teóricos que podem compor um referencial teórico. $\mathrm{O}$ referencial teórico é normalmente usado pelo pesquisador para apresentar um mapa e uma avaliação do território intelectual existente. Fazendo isso, o pesquisador pode especificar uma questão de pesquisa visando a desenvolver, cada vez mais, o corpo de conhecimento existente (TRANFIELD; DENYER; SMART, 2003). Pelo fato de o pesquisador não alcançar o melhor conjunto possível de estudos anteriores, entende-se que é fundamental a discussão dos procedimentos empregados na seleção de trabalhos que compõem o referencial teórico, assim como das limitações introduzidas nessa fase da pesquisa. A relação entre o referencial teórico adotado e a validade das conclusões alcançadas é o objeto da próxima seção.

\section{O REFERENCIAL TEÓRICO E A VALIDADE DA PESOUISA}

Sugere-se que existem dois tipos de erro que um pesquisador pode cometer ao selecionar trabalhos para compor seu referencial teórico. Chamam-se erros de omissão (EO) e erros de inclusão (EI). Um erro de omissão ocorre quando um trabalho relevante e confiável é deixado de fora da revisão. Um erro de inclusão ocorre quando um trabalho irrelevante ou não confiável é incluído na revisão. A Figura 10 representa, esquematicamente, os dois tipos de erros e suas relações com o melhor conjunto possível de trabalhos que deveria constituir o referencial teórico.

O estado da arte em um tópico de pesquisa é representado parcialmente pelos estudos nos quais as teorias relevantes foram testadas empiricamente. Incluem-se aí os testes da teoria nos trabalhos empíricos não relacionados de forma próxima ao fenômeno. Também formam o estado da arte os trabalhos teóricos e teórico-analíticos diretamente relacionados ao tema. Na Figura 1, esses trabalhos são representados por símbolos triangulares, quadrados e redondos. As linhas concêntricas indicam níveis de relevância e de confiabilidade. As áreas demarcadas represen- tam o conjunto de estudos anteriores usado para compor o referencial teórico, sendo que (c) representa a escolha de maior redução dos erros, obtida pelo esforço do pesquisador.

Propõem-se dois critérios para a análise de trabalhos empíricos anteriores, com o objetivo de mitigar erros da omissão e erros de inclusão. O primeiro critério é a relevância, que se entende como o grau em que um estudo contribui, significativamente, para o desenho de uma pesquisa empírica. O segundo é a confiabilidade, ou seja, o quanto um estudo obteve de resultados e conclusões válidas ao testar a teoria apropriada.

Estudos empíricos anteriores, no tópico de pesquisa selecionado, fornecem subsídios teóricos ou metodológicos que influenciam diretamente o desenvolvimento de hipóteses e as escolhas metodológicas, sendo considerados relevantes, pois podem contribuir diretamente para a operacionalização de variáveis ou identificação de proxies.

Um estudo confiável é aquele no qual as conclusões, ainda que restritas, são solidamente consubstanciadas. 


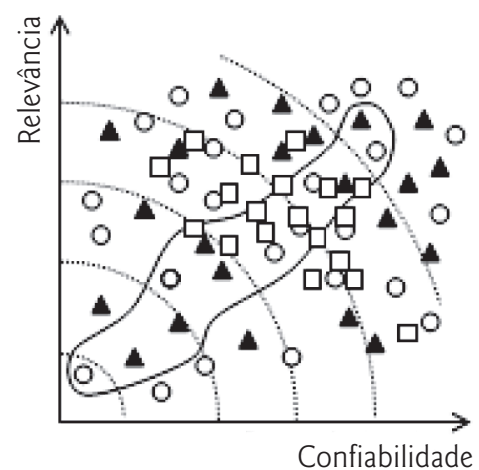

(a) Erros de omissão e de inclusão

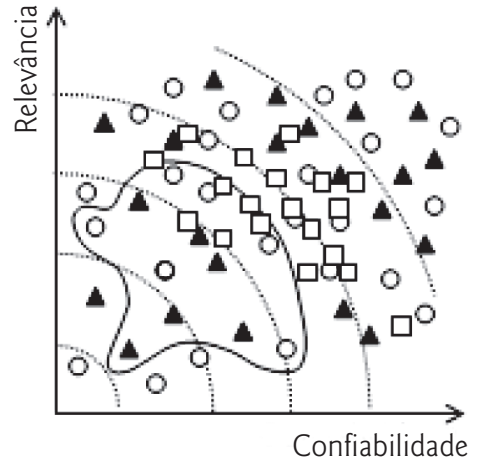

(b) Erros de omissão e de inclusão

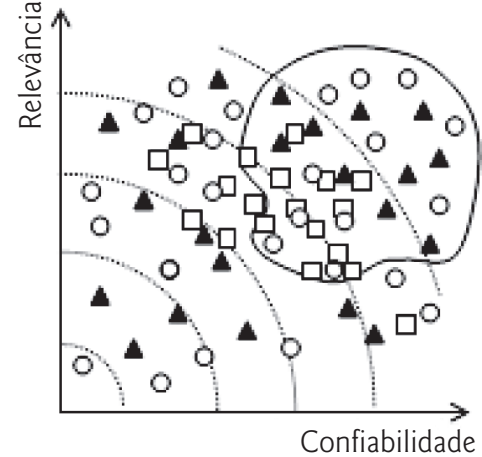

(c) Erros reduzidos

Símbolos:

- Trabalhos empíricos diretamente relacionados com o tópico de pesquisa.

O Trabalhos teóricos diretamente relacionados com o tópico de pesquisa.

$\checkmark$ Trabalhos teóricos-analíticos diretamente relacionados com o tópico de pesquisa.

Figura 1 - Tipos de erros de seleção na composição da revisão de literatura

Nesse aspecto, Abernethy et al. (1999) discutem a existência de três critérios na avaliação da robustez das conclusões de estudos empíricos, que são a validade interna, a validade do construto e a validade externa. Tais critérios são consistentes com a abordagem positivista da pesquisa e são amplamente adotados pelos revisores dos periódicos científicos em Contabilidade, notadamente os da América do Norte. O nível de atenção que um estudo coloca nesses três "pilares" do método científico é o que distinguiria o conhecimento científico do senso comum. Em suma, Abernethy et al. (1999) sugerem duas questões que devem ser respondidas na avaliação do conteúdo informacional de um artigo: (1) a estratégia de pesquisa proposta é apropriada à questão de pesquisa formulada? e (2) o autor demonstrou ter dado atenção suficiente aos aspectos de validade do construto, validade interna e validade externa?

Em relação à primeira questão, se for assumido, como Abernethy et al. (1999), que o processo de pesquisa ocorre num fluxo linear, no qual o problema de pesquisa é elaborado primeiro e depois é escolhida a estratégia de pesquisa mais adequada para respondê-lo, então, será julgado um trabalho pelo grau de ajuste da estratégia escolhida para responder à questão formulada. Outro aspecto importante, nessa avaliação, é a consciência demonstrada pelo pesquisador a respeito dos trade-offs resultantes das escolhas de pesquisa. Por exemplo, as três estratégias mais comuns na pesquisa em contabilidade, que são: o levantamento por questionários, a pesquisa de campo e a pesquisa experimental (ABERNETHY et al.,1999), apresentam pontos fortes e fracos distintos, quase que opostos. A capacidade de controle e manipulação de variáveis, características da pesquisa experimental, contrasta com o potencial da pesquisa de campo em captar a percepção dos atores e em trazer informações qualitativas ricas em conteúdo, que, freqüentemente, fornecem subsídios para o desenvolvimento de proposições teóricas. Assim, a articulação entre a estratégia da pesquisa e a questão a ser respondida se manifesta pela exploração dos pontos fortes de cada método ou técnica. É fundamental a discussão de como as escolhas resultaram em trade-offs e quais as limitações inseridas no estudo.

Em relação às dimensões de validade, Abernethy et al. (1999) afirmam que os avaliadores de trabalhos científicos submetidos aos periódicos peer-reviewed irão observar: (1) como o autor representou as relações teóricas entre os construtos; (2) como as variáveis ou proxies foram operacionalizadas e (3) qual o nível de rigor dos métodos aplicados para testar as hipóteses. Com isso, buscam avaliar o quanto o autor se esforçou para reduzir o risco de inclusão de viés nas observações coletadas (ABERNETHY et al., 1999).

Essas dimensões de análise têm relação direta com o referencial teórico. Um referencial teórico criterioso é fundamental para a definição da correspondência entre a teoria e os dados empíricos (SEARCY; MENTZER, 2003). A ocorrência de erros de omissão e de inclusão impacta na validade interna, pois o desenho da pesquisa é afetado pelo uso de um conjunto impróprio de referências. Um erro de inclusão é mais crítico quando o trabalho, equivocadamente incluído, é usado como base para hipóteses, seleção de construtos, variáveis ou técnicas de análise. Em conseqüência, o pesquisador, provavelmente, proporá relações causais equivocadas, operacionalizará variáveis de forma imprecisa, utilizará proxies mal combinadas ou conduzirá testes não apropriados.

Uma outra conseqüência que pode se originar dos erros na seleção dos trabalhos é um mapeamento impreciso do território intelectual existente. Sem considerar os erros na fase do projeto, o estudo também teria sua relevância ameaçada, pois os resultados podem já ter sido previamente demonstrados em outros trabalhos ou o rumo da pesquisa em questão poderia já ter sido rejeitado ou esgotado. 


\section{VALIDADE DO REFERENCIAL TEÓRICO: CRITÉRIOS DE ANÁLISE}

No contexto da pesquisa positiva, os revisores dos periódicos acadêmicos analisam um trabalho em relação aos três axiomas da pesquisa positiva: as dimensões de validade interna, a validade do construto e a validade externa.

Validade interna é uma medida de quanto o desenho do projeto de pesquisa permite inferir causalidade sobre o efeito da variável independente na variável dependente (ABERNETHY et al., 1999). Para assegurar a validade interna, o pesquisador deve controlar as variáveis no ambiente da questão de pesquisa e afirmar com convicção que os achados representam o fenômeno real do interesse (SEARCY; MENTZER, 2003).

Validade de construto é uma inferência sobre como as variáveis independentes e dependentes foram operacionalizadas com sucesso, ou seja, o quanto elas representam as construções teóricas pretendidas (ABERNETHY et al., 1999; SEARCY; MENTZER, 2003). A validade externa está relacionada a aspectos de amostragem estatística e não será discutida no presente trabalho.

Na pesquisa em Contabilidade Gerencial, para Abernethy et al. (1999), o uso de proxies da Contabilidade Financeira não contribui para a obtenção de níveis elevados de validade para os problemas de pesquisa típicos. Os autores, ainda, destacam que o uso de proxies nas pesquisas na área sempre representa a possibilidade de que tais proxies

\section{CAMADAS NO REFERENCIAL TEÓRICO}

O conceito de camada é sugerido para guiar o processo de elaboração de referencial teórico. A Figura $2 \bullet$ apresenta um esquema para o conceito de camadas proposto neste trabalho. Cada pesquisa científica existe dentro de uma rede de estudos anteriores a ele e outra posteriores a ele. Parte dos estudos anteriores será citada no relatório de pesquisa em questão. Essa rede de estudos forma o histórico de um tópico de pesquisa. Identificar tal rede permite conhecer tal tópico e evitar os erros de omissão, não negligenciando um certo grupo de estudos. Os estudos anteriores em um dado tópico de pesquisa estão indexados às seguintes características típicas, presentes em todo estudo científico publicado: (i) periódicos acadêmicos em que foram publicados; (ii) autores; (iii) instituições, por exemplo universidades, centros de pesquisa e conferências; (iv) tendências e métodos teóricos dominantes e (v) uma posição particular no tempo. Define-se como camada um conjunto inteiro de informação sobre os estudos existentes em uma das características típicas acima mencionadas. Por exemplo, a camada de autores contém autor e co-autores de cada estudo identificado, assim como todos os autores que tenham potencial relação com os já identificados e que ainda não foram identificados como relevantes no tema. Trabalhar na busca de outros artigos, em uma camada significa identificar trechos da rede de relações entre estudos, utilizando pontos em comum entre um estudo possam afetar os testes das relações das hipóteses enunciadas, uma vez que os construtos estarão sendo aproximados e não mensurados diretamente. Então, a capacidade discriminante da pesquisa empírica é afetada não somente pela qualidade da teoria subjacente e pelas análises estatísticas, mas também a proximidade com que as proxies medem os construtos teóricos. Assim, a validade interna e a validade de construto são propriedades críticas a todas as pesquisas empíricas que envolvem teste de teoria em Contabilidade Gerencial. Percebe-se, claramente, que o referencial teórico, enquanto suporte para o desenvolvimento de hipóteses, operacionalização de variáveis e escolha de testes, relaciona-se diretamente com as dimensões de validade interna e validade do construto.

Propõe-se que os estudos empíricos em Contabilidade Gerencial contenham um protocolo que descreva os procedimentos usados na composição do referencial teórico. A apresentação dos critérios de seleção de trabalhos anteriores deve ser acompanhada da discussão do possível viés de seleção introduzido, tipificado pelos erros de inclusão $e$ de omissão. Adicionalmente, a inclusão do protocolo tem potencial para levar a um conjunto mais robusto de conexões lógicas entre teoria, hipóteses, construtos e projeto da pesquisa.

já encontrado e outros em potencial, segundo uma característica típica. Todos os trabalhos inseridos no conjunto de trabalhos relevantes podem ser alcançados por mais de uma camada, pois todos preenchem características nas cinco camadas.

A heurística, aqui apresentada, é sustentada pela necessidade de estabelecer critérios para fazer a seleção de trabalhos por essas camadas. Não é praticável identificar, no momento da busca por estudos anteriores, cada trabalho que é relevante e/ou confiável. Mas a relevância e a confiabilidade podem ser aproximadas em cada camada. Por exemplo, na camada de periódicos, o posicionamento de um periódico particular em um ranking, com respeito ao tema geral da pesquisa, pode ser usado como uma proxy inicial para a relevância e a confiabilidade. O uso dos autores principais é uma tentativa de aproximação da confiabilidade, também. Uma breve análise das citações pode indicar trabalhos e autores seminais. Mas é necessário avaliar a relevância e a confiabilidade nos termos da validade interna e da validade de construto em cada trabalho empírico, não importando quem seja o autor, a que instituição ele pertence ou em que periódico o trabalho foi publicado.

Ao avaliar um trabalho empírico particular, o pesquisador deve também observar as escolhas teóricas e metodológicas específicas do autor. Ao fazer isso, o pesquisador 


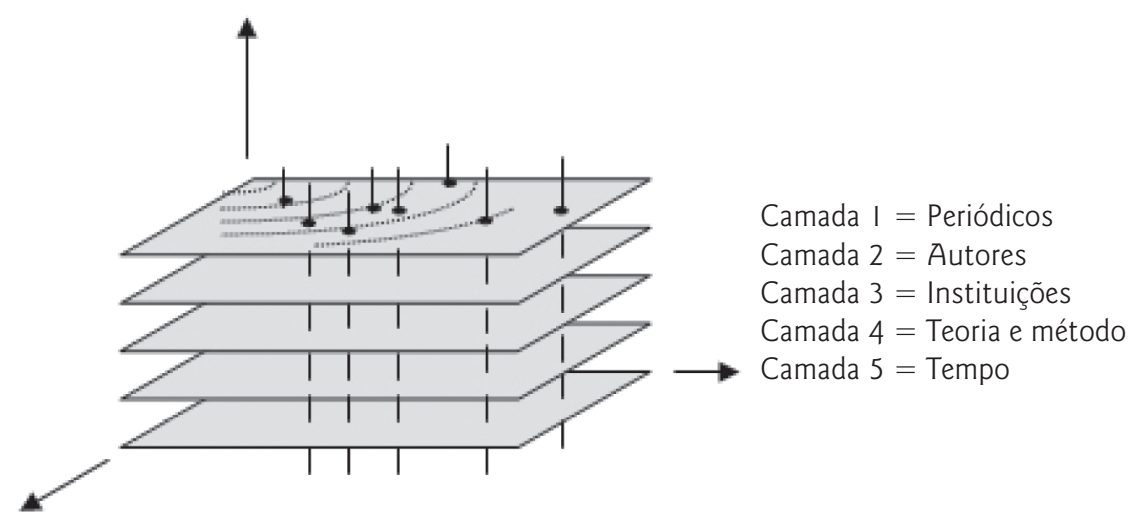

Figura 2 Camadas como um conjunto de características de documentos científico

atua na camada de teoria e de métodos. Essa informação, associada à camada do tempo, pode facilitar a construção de uma perspectiva temporal sobre as questões metodoló- gicas e teóricas no tema, dando uma noção sobre o estado da arte no tópico da pesquisa.

\section{MÉTODO HEURÍSTICO PARA A ELABORAC̣ÃO DE REFERENCIAL TEÓRICO}

Sugere-se um processo iterativo para facilitar a tarefa de compor o referencial teórico. As etapas do processo incluem:

a) construção da base de dados bibliográficos:

- Estabelecer o conjunto inicial de periódicos do mainstream no campo de conhecimento para busca de trabalhos no tópico de pesquisa escolhido;

- Preparar a base de referência em uma planilha eletrônica para relacionar os trabalhos identificados, informando periódico, ano, autores, título e resumo;

- Realizar a primeira busca nesses periódicos por palavra-chave no título e no resumo, alimentando a base de referências;

- Buscar recorrências em autores e em co-autorias, esquematizar diagramas ordenando as publicações por autores na linha do tempo e localizar os centros de pesquisas relacionados aos principais autores;

- Identificar recorrências em citações identificando outros autores e periódicos citados, ampliando a relação de periódicos e voltando à primeira camada. Proceder iterativamente;

- Estabelecer um critério de leitura dos estudos, por ordem cronológica, por autores mais citados, ou qualquer outro critério que gere aprendizagem;

- A leitura de surveys (coletâneas e revisões de um campo de pesquisa) pode ajudar a criar uma visão mais ampla do tópico de pesquisa e ampliar a base de referências por meio dos estudos referenciados;

- Depois de certo aprendizado no processo, expandir a base de trabalhos anteriores utilizando expressões de busca mais refinadas.

b) leitura e mapeamento de estudos anteriores:

- Identificar na leitura a(s) abordagem(ns) teórica(s) utilizada(s), a estratégia de pesquisa adotada, construtos, variáveis e respectivas proxies empregadas;

- A cada estudo lido, armazenar as características de teoria, método e operacionalização de conceitos em planilha eletrônica, de forma indexada à base de referências existente;

- Identificar as principais estratégias de pesquisa usadas para conduzir pesquisas no assunto escolhido, o que ajudará a identificar os tipos de explicações usadas para explorar o tópico da pesquisa e os métodos associados com as explicações;

- Procurar por padrões de uso de teorias, métodos e estratégias de pesquisa dentro do tópico, já identificados na leitura, associando a autores e periódicos;

- Desenhar um mapa das evidências teóricas consistentes com as relações causais testadas, adotando a simbologia de Luft e Shields (2003);

- Situar cada estudo no mapa das evidências teóricas consistentes.

c) escrita:

- Compor a análise temática, seguindo Tranfield, Denyer e Smart (2003);

- Finalizar a análise temática com o desenvolvimento de hipóteses.

\subsection{Construção da base de dados bibliográficos}

Geralmente um pesquisador começará com um conjunto pequeno de artigos. Após alguma leitura, esse pequeno conjunto pode conduzir a um tópico da pesquisa. Esse é o início. O processo sugerido para a composição do referencial teórico parte daí. A primeira etapa é coletar um conjunto de estudos anteriores para formar uma base bibliográfica. Esses trabalhos devem, no início, ser empíri- 
co-analíticos, o que é crucial para um meticuloso mapeamento da pesquisa existente no tópico escolhido.

Nesse ponto, sugere-se que o pesquisador trabalhe somente na camada de periódicos. O trabalho, nessa camada, inicia-se pela seleção de periódicos para varredura meticulosa e a obtenção dos estudos anteriores. Assumese que o pesquisador, especialmente nos casos de alunos de mestrado e de doutorado, tenha um conhecimento limitado sobre autores e instituições nessa fase, portanto, é mais seguro usar os periódicos como proxy para a qualidade das pesquisas. Essa sugestão se baseia no fato de que a pesquisa na área organizacional é caracterizada por uma ausência de consenso epistemológico. Há pouco acordo a respeito das questões-chaves de pesquisa e os estudos de campo, freqüentemente, não tratam de problemas de pesquisa similares nem fazem as mesmas perguntas (TRANFIELD; DENYER; SMART, 2003). Conseqüentemente, os padrões de qualidade são flexíveis e os pesquisadores tendem a confiar na qualidade de um periódico particular, mais que de aplicar critérios da avaliação de qualidade aos artigos individuais (TRANFIELD; DENYER; SMART, 2003, p. 213). Adicionalmente, há uma grande variedade de técnicas de coleta de dados e métodos de análise. Como conseqüência, é improvável que um pesquisador domine todas as técnicas para coleta e análise de dados. Então, a habilidade desse pesquisador em avaliar a qualidade de um artigo é assumida como sendo apenas parcial. Essa é a razão pela qual se enfatizam os periódicos como uma das proxies para a qualidade da pesquisa.

É possível trabalhar nas dimensões de relevância e de confiabilidade ao longo da camada de periódicos. É sugerido que a seleção de periódicos listados no topo do ranking de periódicos acadêmicos pode contribuir para o alcance de um nível desejado da qualidade. O pesquisador pode começar procurando trabalhos empíricos nos periódicos do topo do ranking em Contabilidade e em Economia. Essa busca conduzirá a um conjunto de artigos empíricos, teórico-analíticos e teóricos, diretamente e indiretamente relacionados ao fenômeno. Para obter informações sobre rankings dos periódicos acadêmicos em Contabilidade e Economia, sugerem-se: Beattie e Goodacre (2006), Bonner et al. (2006), Reinstein e Calderon (2006). Complementarmente, o pesquisador pode procurar trabalhos empíricos nos periódicos das áreas de Sociologia e de Psicologia. Como Covaleski et al. (2003) exemplificam, o tema orçamento já foi estudado nas perspectivas teóricas de economia, sociologia e de psicologia. Contudo combinar diferentes teorias, particularmente teorias de campos distintos, é uma tarefa complexa. O êxito, nessa tarefa, decorre das teorias relacionadas compartilharem premissas, dado que as proposições teóricas derivam das premissas que cada teoria assume. As dificuldades relacionadas à condução de pesquisas com mais de uma abordagem teórica fazem com que esse tipo de projeto seja menos freqüente. É mais freqüente, no entanto, encontrar estudos conduzidos em tópicos de pesquisa próximos, com abordagens teóricas diferentes. Nesse caso, é sugerido o texto de Covaleski et al. (2003), que discute, em detalhes, os processos de comparação e integração de estudos com abordagens teóricas diferentes.

O trabalho na camada de periódicos tem como objetivo obter níveis mais consistentes de relevância e de confiabilidade. Permite, também, que o pesquisador adie a análise detalhada de cada trabalho empírico presente na base bibliográfica, até que seja alcançado um número substancial de trabalhos previamente selecionados. No entanto, a busca por trabalhos anteriores nos principais periódicos é uma simplificação dos critérios de relevância e confiabilidade, além de introduzir um viés. Entende-se que a base bibliográfica deve ser, então, expandida pela busca em outros periódicos. Para isso, sugere-se que o pesquisador parta para as camadas de autores e suas instituições. Procurar nos periódicos fora do mainstream sem proxies de relevância e de confiabilidade aumenta a probabilidade de erros de inclusão e/ou omissão. Sugere-se que, nos periódicos fora do mainstream, os autores e/ou as instituições podem ser usados como tentativa de proxies para a qualidade. Reforça-se que essas proxies são tentativas, pois o pesquisador está coletando trabalhos empíricos lendo apenas o título, autor e resumo. Depois da base de dados ter sido construída, essas proxies serão substituídas por uma análise cuidadosa da relevância e da confiabilidade, conforme será discutido na próxima seção.

Na camada de autores, recorrência de citações e coautoria são critérios iniciais da análise. O conjunto inicial dos autores conduzirá o pesquisador à camada de instituições. Recomenda-se a coleta de informações em currículos e biografias dos autores. Isso pode ser feito por uma busca pela Internet, a qual irá levar o pesquisador ao sítio institucional do autor e ao centro de pesquisa e ensino ao qual ele está vinculado. Procedendo assim, o pesquisador começa a ganhar uma perspectiva de todo o conjunto de informação sobre o tema da pesquisa, incluindo os periódicos consultados, os estudos anteriores, os autores e as instituições. É possível descobrir aspectos como regularidade em coautorias, visões compartilhadas entre autores, instituições e programas de pesquisa existentes e relevantes no tema, assim como a posição de periódicos específicos, centrais ou periféricos, em um programa de pesquisa. Assim, o pesquisador começa a construir a sua expertise no tema.

Uma outra razão da necessidade de uma perspectiva entre autores, instituições e periódicos é a proposição de que os periódicos de elite são dominados por membros da elite, especialmente nos termos de quadros editoriais. Esses periódicos têm uma minoria de membros de fora da elite e convidam um número muito pequeno de indivíduos sem doutorado para participar dos comitês editoriais (LEE, 1997). Em seu estudo sobre a presença dominante das elites na estrutura institucional da academia contábil, Lee (1997) concluiu que os membros da equipe editorial atuavam como os guardiões do conhecimento e da reputação e tinham a capacidade de influenciar significativamente os padrões de produção de conhecimento acadêmico em Contabilidade. 
A finalidade, aqui, não é apresentar um julgamento de valor sobre o comportamento dos quadros editoriais. A ciência é uma atividade auto-regulada e os pesquisadores devem estar cientes disso. A necessidade de alcançar uma perspectiva integradora das diversas partes interessadas na comunidade científica, expressa nos padrões da autoria, temas de pesquisa, periódicos e instituições, amplia as probabilidades de uma pesquisa ser publicada futuramente em um periódico bem posicionado no ranking.

Recomenda-se excluir da base os artigos que não fornecem evidência empírica consistente com a teoria proposta neles. O mesmo procedimento foi aplicado por Luft e Shields (2003) em seu mapeamento da pesquisa teórico-empírica em contabilidade gerencial. A adoção desse critério deve resultar em um conjunto de artigos e teses que utiliza elevados níveis de teorização prévia e de formalização teórica dos métodos de pesquisa, característicos da pesquisa positiva (LAUGHLIN, 1995). Embora a pesquisa qualitativa seja executada, freqüentemente, com diversas orientações de teorização prévia e de métodos, sugere-se que o critério de inclusão de trabalhos anteriores continua válido, independentemente do trabalho analisado ser quantitativo ou qualitativo.

Apesar de ser destacada a importância de artigos empíricos, teórico-analíticos e teóricos, outra importante fonte de informação são as surveys. Tais revisões de trabalhos empíricos podem ajudar a expansão da base de dados bibliográficos, pois permitem levantar informações sobre os periódicos, autores e teorias.

Até esse ponto, o esforço de coleta é, na maior parte, iterativo. Após uma primeira movimentação ao longo das três primeiras camadas, o pesquisador coletou um conjunto de informações sobre periódicos, autores e instituições. Por exemplo, as páginas dos sítios institucionais dos autores podem conduzir a outras publicações do mesmo autor em um periódico previamente não incluído na busca. Outros autores poderão ser encontrados. Esse novo conjunto de informações pode dirigir o pesquisador a outros periódicos e desses a outros autores e instituições. Um segundo movimento em torno das primeiras três camadas é, então, finalizado e o pesquisador adquirirá um outro conjunto de informação. Espera-se que o processo alcance a saturação após algumas rodadas, uma vez que o pesquisador percebe que a perspectiva melhora marginalmente após a última rodada.

Nesse momento, espera-se que o pesquisador tenha conseguido um dos melhores conjuntos possíveis de trabalhos anteriores no tópico da pesquisa escolhido. As conexões entre autores, centros de pesquisa, conferências, métodos, teorias e momento do tempo podem ser investigadas no aprofundamento e refinamento da base bibliográfica.

A dimensão temporal deve ser incorporada na análise dos trabalhos anteriores presentes na base. Isso pode ser conseguido trabalhando na camada de tempo. As posições relativas dos trabalhos, nessa camada, fornecerão um sentido da linha de desenvolvimento do tema da pesquisa, incluindo o uso de novos métodos e de novas influências teóricas. Ao compor um referencial teórico, a dimensão temporal é uma característica essencial da análise temática, na qual o pesquisador apresenta o referencial desde suas origens modernas até as tendências emergentes no campo de estudo.

A partir de certa experiência no tópico, podem ser exploradas bases de working papers, partindo da reputação dos autores identificados no tópico de pesquisa, como tentativa de manter sob controle a confiabilidade do estudo. Nesses casos, os níveis de relevância e de confiabilidade ficam por conta do juízo de quem faz a revisão de literatura.

\subsection{Mapeamento de estudos anteriores}

A partir desse momento, a leitura detalhada de cada trabalho se inicia. Sugere-se que o pesquisador explore as relações causais propostas e operacionalizadas em cada trabalho anterior, com o objetivo de construir um mapa de trabalhos anteriores no tópico da pesquisa.

Mapear os trabalhos anteriores permitirá que o pesquisador consiga uma perspectiva do estado da arte no assunto escolhido. Isso é imperativo para um doutorando, desde que se espera que uma tese de doutorado relate resultados da pesquisa nas fronteiras da ciência. O candidato deve demonstrar, claramente, que identificou os limites do conhecimento científico e se propôs a ampliar tais limites. Para tanto, deve avaliar a relevância e o tamanho da literatura e limitar a área ou o tópico do assunto. O mapa de trabalhos existentes deve incluir as perspectivas interdisciplinares $e$ as diversas abordagens dadas a um tópico de pesquisa. $\mathrm{O}$ mapa resultante pode, também, ser usado como evidência para apresentar uma breve visão geral histórica dos debates teóricos, práticos e metodológicos que cercam o campo e os sub-campos do estudo.

Recomenda-se o texto de Luft e Shields (2003) como um guia para executar o mapeamento de trabalhos anteriores em contabilidade gerencial. Com o objetivo de contribuir para o entendimento de como as diferentes linhas de pesquisa em contabilidade gerencial se complementam e se reforçam na busca de explicações causais, Luft e Shields (2003) oferecem uma representação gráfica construída por meio da análise das evidências empíricas de 275 estudos. Dividida em nove mapas, cada um representativo de uma linha de pesquisa em Contabilidade Gerencial, essa representação gráfica foi construída de modo a oferecer respostas para três perguntas a respeito de cada artigo empírico mapeado:

- O que é pesquisado? Por meio da atribuição de um código e de uma legenda para as variáveis, resume-se o tópico da pesquisa;

- Qual a direção e a forma das relações causais propostas? Os autores analisaram as hipóteses corroboradas dos 275 estudos quanto à forma do modelo causal operacionalizado. Luft e Shields (2003) sugerem uma classificação em seis formas de modelos causais: o modelo aditivo, o modelo 
interveniente, o modelo interativo, o modelo independente, o modelo moderador, o modelo recursivo cíclico e o modelo não recursivo recíproco. Adicionalmente, as relações entre variáveis podem ser lineares ou não lineares.

- Qual é o nível da análise? Os estudos analisados por Luft e Shields (2003) foram posicionados nos seus respectivos mapas em relação aos níveis: individual, de unidade organizacional (como unidades estratégicas de negócios), da organização como um todo e do nível que abrange, mas não se restringe à organização, ou seja, vai além da organização. Essa classificação define o nível em que a variável de interesse ocorre (KOZLOWSKI; KLEIN, 2000). Luft e Shields (2003), ainda, oferecem 17 recomendações sobre como construir os mapas, como relatar variáveis, formas de modelos causais e sobre o nível da análise.

Um critério sugerido aqui, que complementa a abordagem oferecida por Luft e Shields (2003), é a inclusão da discussão a respeito do processo de levantamento dos estudos anteriores que irão compor um referencial teórico. No mapeamento da pesquisa em Contabilidade Gerencial realizado, Luft e Shields (2003) utilizaram cinco critérios para inclusão de um estudo na análise: (1) se o estudo foi publicado em um entre seis periódicos acadêmicos de Contabilidade previamente estabelecidos; (2) se o estudo oferece evidências empíricas a respeito da Contabilidade em organizações, não no mercado de capitais, em impostos ou governos; (3) se o estudo explica causas ou efeitos de variações na Contabilidade Gerencial; (4) se o estudo apresenta evidências consistentes com a teoria apresentada na sua sustentação; (5) se um estudo atende parcialmente aos critérios anteriores, apenas as partes em conformidade são incluídas.

Entende-se que o primeiro critério para a inclusão de trabalhos empíricos pode ser mais objetivo e também ampliado. Por exemplo, os seis periódicos previamente definidos por Luft e Shields (2003) foram: Accounting, Organizations and Society, Contemporary Accounting Research, Journal of Accounting and Economics, Journal of Accounting Research, Journal of Management Accounting Research, e The Accounting Review. Provavelmente tal escolha reflete o fato de que esses periódicos aparecem, consistentemente, na grande maioria dos estudos que se dedicaram a elaborar um ranking de periódicos acadêmicos de Contabilidade (por exemplo, ver Lowe (2005), Beattie e Goodacre (2006); Bonner et al. (2006); Reinstein e Calderon (2006)). Luft e Shields (2003) afirmam que os seis periódicos escolhidos oferecem uma amostra grande o suficiente e representativa da pesquisa empírica em Contabilidade Gerencial. No entanto, pode-se questionar: por que não foi incluído na lista o periódico Management Accounting Research? Ou o European Accounting Review? É provável que, se os autores buscassem trabalhos nos 15 ou 20 principais periódicos acadêmicos em Contabilidade, a lista de trabalhos empíri- cos iria ficar tão extensa que inviabilizaria o mapeamento em um tempo razoável.

Situação diferente deve ser enfrentada por um mestrando ou doutorando. Nesses casos, a busca por artigos é bem mais delimitada em relação ao tópico de pesquisa a ser desenvolvido na dissertação ou tese. Conseqüentemente, a delimitação das buscas de referências em poucos periódicos pode resultar um número insuficiente de artigos recuperados, o que pode aumentar a incidência dos erros de omissão previamente mencionados. Entende-se que a aplicação dos procedimentos sugeridos na seção anterior, que trata da construção da base de dados bibliográficos, tem grande potencial para reduzir esses problemas. A heurística de construção da base de dados é um aspecto que se procura tratar com mais detalhe e mais critério, como forma de complementar as ferramentas de mapeamento oferecidas por Luft e Shields (2003).

\subsection{Escrita do referencial teórico}

Dado o impacto que o referencial teórico escolhido tem nas dimensões de validade interna e validade de construto, exemplificado pelas relações causais que serão operacionalizadas com a ajuda do referencial, entende-se que o pesquisador deve substanciar o conjunto de trabaIhos escolhido. Sugere-se para isso a divulgação dos procedimentos específicos usados ao elaborar o referencial, por meio de um protocolo. Mas o protocolo não é o referencial teórico. Entre as estruturas narrativas sugeridas para a apresentação do referencial, destaca-se a análise temática, que é uma estrutura de apresentação na qual o pesquisador explicita (TRANFIELD; DENYER; SMART, 2003): (i) o que é conhecido e já aceito como válido pelas contribuições centrais dos estudos anteriores; (ii) a extensão em que o consenso é compartilhado nas várias dimensões de análise, como, por exemplo, abordagens teóricas e modelos causais; (iii) a perspectiva histórica do tópico da pesquisa, com menção especial para formulações iniciais, refinamentos contemporâneos da teoria, principais temas emergentes e (iv) o estado da arte de métodos e das técnicas.

Vale a pena mencionar que o pesquisador não está obrigado a incluir cada trabalho revisto no relatório da pesquisa. Em geral, espera-se que somente parte da base de dados bibliográficos seja usada para a composição do referencial teórico, pois, a partir do momento em que o pesquisador escolhe uma perspectiva teórica específica, alguns dos trabalhos revistos estarão desalinhados com a abordagem escolhida.

No relatório da pesquisa, sugere-se que a seção do referencial teórico não seja dividida em tópicos, tais como: autores, teoria e assim por diante. Uma fragmentação excessiva do texto resultará em uma mera aglomeração de conceitos sem um sentido de unidade. A seção do referencial teórico pretende fornecer a sustentação para a análise causal, desenho da pesquisa e escolha das proxies. A ordem de argumentação específica é influenciada, consideravelmente, pela pergunta da pesquisa. O texto deve 
ser estruturado a fim de validar um caminho específico na procura por uma resposta à pergunta da pesquisa. As decisões tomadas para dar forma a uma estratégia da pesquisa devem ser claramente indicadas, permitindo a avaliação pela comunidade científica.

\section{EXEMPLO DE APLICAC̣ÃO DA HEURÍSTICA}

Apresenta-se, a seguir, a aplicação da heurística para a elaboração de referencial teórico conduzida na dissertação de mestrado de um dos co-autores. A dissertação abordou o tema de coordenação inter-firmas, particularmente focado em 175 redes de franquias, a partir de informações retiradas do Anuário da Associação Brasileira de Franchising $(A B F)$. O estudo consistiu de uma análise sobre o mix contratual das redes de franquias brasileiras, que a exemplo das redes em outros países, utilizam lojas próprias e franqueadas. As proposições teóricas desenvolvidas com base na Teoria da Agência objetivaram entender a incidência de custos de monitoramento e o uso incentivos na decisão desse mix contratual.

\subsection{Construção da base de trabalhos anteriores}

O primeiro passo no processo foi a seleção de periódicos de partida. O critério utilizado para a seleção inicial desses periódicos foi a composição dos rankings de periódicos em Kodrzycki e Yu (2005) e os periódicos pesquisados por Luft e Shields (2003).

A lista de periódicos de Contabilidade citados em Luft e Shields (2003), apresentados anteriormente, cobririam os potenciais estudos voltados para coordenação inter-firmas no campo de conhecimento da contabilidade gerencial. A essa lista foram adicionados os dez primeiros periódicos de economia no ranking de Kodrzycki e Yu (2005): American Economic Review, Quarterly Journal of Economics, Journal of Political Economics, Review of Economics Studies, Journal of Economic Prospect, Journal of Economic Theory, The RAND Journal of Economics, Journal of Economic Behavior and Organization, Journal of Law and Economics e Journal of Institutional and Theoretical Economics. Destaque-se que, para cada tópico de pesquisa ou área temática, a lista de periódicos de partida deve ser revista.

A partir desses periódicos de partida, iniciou-se a busca de artigos por meio de palavras-chaves. Foram efetuadas buscas nos campos de título e resumo, com as palavras-chave franchising, franchise, franchisor, franchiser ou ainda franchisee. Um conjunto de 45 artigos, entre teóricos, teórico-analíticos e empíricos, foi selecionado. Não foram encontrados artigos relacionados ao tópico de pesquisa em nenhum periódico de Contabilidade, daqueles da lista de Luft e Shields (2003).

Depois da primeira rodada de busca, passou-se à análise da camada de autores em relação ao tópico franquias. Foram visitados os sítios dos centros de pesquisa em que são filiados, assim como a lista de artigos e working papers citados nos curricula vitae. Os estudos que, no resumo, apresentavam relação com o tema foram acrescentados à base. De for- ma não estruturada, foi realizada análise das citações, com o objetivo de identificar os trabalhos tidos como seminais no mainstream do campo do conhecimento.

Dezenove artigos foram acrescidos aos 45 iniciais, os quais passaram a ser organizados em ordem cronológica de publicação, a partir do primeiro trabalho publicado envolvendo o tema, por Paul Rubin, no Journal of Law and Economics, em 1978.

Iniciou-se, então, o processo de leitura preliminar, visando ao mapeamento dos trabalhos sobre franquias. A primeira etapa da leitura permitiu verificar recorrências em citações de trabalhos não contidos nos periódicos já verificados. Dessa forma, mais autores e co-autores foram identificados, assim como outros periódicos foram adicionados à base. Uma característica observada é que os novos periódicos adicionados não eram de perfil essencialmente econômico, mas da linha de Administração. A presença do tema em periódicos de Economia e Administração é resumida na Tabela 10

Com a inclusão de novos artigos e periódicos, sem ainda uma avaliação formal da confiabilidade dos trabalhos, aumentam os riscos potenciais de ocorrência de erros de inclusão decorrentes do aumento da base de artigos. Tais riscos foram trabalhados durante o mapeamento das relações causais propostas nos artigos teóricos e teórico-analíticos, e as corroboradas nos artigos empírico-analíticos. Por fim, com base nas leituras iniciais, foi possível identificar os autores com maior número de publicações no tema, os quais receberam prioridade na leitura. Concluída a leitura dos artigos desses autores, foi retomada a leitura dos demais artigos seguindo a ordem cronológica.

\subsection{Mapeamento das relações causais teóricas propostas e corroboradas}

A leitura realizada nessa etapa de mapeamento, mais aprofundada, permitiu obter as informações que formam a camada teoria e método. Nessa fase, a leitura detalhada dos estudos permitiu avaliar a relevância e a confiabilidade de cada trabalho em particular. Isso foi feito pela atenção especial à verificação de como o autor de cada estudo tratou, mesmo que implicitamente: (a) a pertinência da estratégia de pesquisa; (b) os trades off enfrentados e as limitações introduzidas pelo método, levadas à análise dos resultados; (c) o desenvolvimento das hipóteses, a fundamentação do raciocínio nas relações causais propostas pela teoria; (d) a interpretação dessas relações e a sua adaptação ao fenômeno em estudo; (e) os procedimentos usados na seleção de amostra; (f) a representatividade da amostra na discussão dos resultados e nas conclusões; (g) o uso de procedimentos para a validação dos construtos; (h) as relações 
Tabela 1 Estudos em franquias em periódicos de Economia e Administração

\begin{tabular}{|c|c|c|c|c|c|c|c|c|c|c|c|c|c|c|c|c|c|c|c|}
\hline \multicolumn{20}{|c|}{ Economia } \\
\hline Periódicos & $\stackrel{\infty}{\stackrel{\infty}{\sigma}}$ & 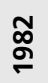 & $\begin{array}{l}\stackrel{\llcorner}{\infty} \\
\stackrel{\circ}{\sigma}\end{array}$ & $\begin{array}{l}\infty \\
\stackrel{2}{\circ} \\
\stackrel{2}{\sigma}\end{array}$ & รั & กั & ুั & นก & ริ & $\stackrel{\infty}{\stackrel{一}{口}}$ & §ิ & ষ্ণ & চ্ণ & ণั & ஜ̊̀ & ষ্ণ & ஜ̊ & ஜั & Total \\
\hline JPE & & & & & & & & & & & 1 & & & & & & & & 1 \\
\hline AER & & & & 1 & & & & & & & & & & & & & & & 1 \\
\hline RJE & & & & & 1 & 1 & & & & & & & & & & 1 & 1 & & 4 \\
\hline QJE & & & & & 1 & & & & & & & & & & & & & & 1 \\
\hline JITE & & & & & & & & & & & & & & 1 & & & & & 1 \\
\hline JEBO & & & & & & & 2 & & & 1 & & 1 & & 1 & & & & & 5 \\
\hline JLE & 1 & 1 & 2 & & 1 & & & & & & 1 & & & & & & & & 6 \\
\hline Total & 1 & 1 & 2 & 1 & 3 & 1 & 2 & 0 & 0 & 1 & 2 & 1 & 0 & 2 & 0 & 1 & 1 & 0 & 19 \\
\hline
\end{tabular}

\begin{tabular}{|c|c|c|c|c|c|c|c|c|c|c|c|c|c|c|c|c|c|c|c|}
\hline \multicolumn{20}{|c|}{ Administração } \\
\hline Periódicos & $\stackrel{\infty}{\overleftarrow{2}}$ & 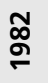 & 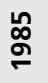 & $\begin{array}{l}\infty \\
\stackrel{\circ}{\leftarrow}\end{array}$ & รু & ภั & ั̆ & ณ̊ & Бे & $\stackrel{\text { Д̆ }}{\circ}$ & ஓे & ஓ्̀ & $\bar{i}$ & ণั & $\stackrel{m}{\stackrel{n}{े}}$ & ষ্ণ & ํํํ & ¿ & Total \\
\hline MS & & & & & & & & 3 & 1 & & 1 & & & & & 1 & & 1 & 7 \\
\hline $\mathrm{JB}$ & & & & 1 & & & & & & & & & & & & & & & 1 \\
\hline JM & & & & & & & & & & & & & & & 1 & 1 & & & 2 \\
\hline AMJ & & & & & & & & & & & 1 & & & & & & & & 1 \\
\hline SMJ & & & & 1 & 1 & & & & & 1 & & 1 & 1 & & & 1 & & & 6 \\
\hline JSBM & & & & & & & & & & & & & 1 & 1 & 2 & 2 & 1 & 2 & 9 \\
\hline Total & 0 & 0 & 0 & 2 & 1 & 0 & 0 & 3 & 1 & 1 & 2 & 1 & 2 & 1 & 3 & 5 & 1 & 3 & 26 \\
\hline
\end{tabular}

Legenda: JPE - Journal of Political Economy; AER - The American Economic Review; RJE - RAND Journal of Economics;

QJE - The Quarterly Journal of Economics; JITE - Journal of Institutional and Theoretical Economics; JEBO - Journal of Economic Behavior \& Organization; JLE - Journal of Law and Economics; MS - Management Science; JB - Journal of Business; JM - Journal of Management; AMJ - The Academy of Management Journal; SMJ - Strategic Management Journal; JSBM - Journal of Small Business Management.

entre os construtos ou variáveis refletindo a causalidade proposta na teoria; (i) a robustez dos resultados estatísticos; (j) a robustez da argumentação qualitativa e a quantidade e qualidade das evidências empregadas. Foram aceitos 48 artigos publicados para compor o referencial teórico da dissertação. Desses, 32 são estudos empíricos, um do tipo survey, cinco artigos teóricos, nove teórico-analíticos, e uma meta-análise teórica de trabalhos anteriores.

Inicialmente, a leitura dos trabalhos permitiu identificar as principais abordagens teóricas usadas como suporte ao entendimento do tema franquias. Especificamente, observou-se que a Teoria da Agência é predominante nos estudos no tema publicados em periódicos de Economia, enquanto a Teoria dos Recursos Escassos aparece com maior freqüência nos periódicos de Administração. Enquanto a primeira teoria aborda a relação de franquia como uma resposta a problemas de coordenação dos gerentes próprios nas lojas da rede, a segunda teoria trata o franqueado como uma fonte de recursos que reduz restrições ao crescimento da cadeia de lojas e da própria marca.

O processo de mapeamento identificou: (i) as relações causais; (ii) os procedimentos de seleção de amostra; (iii) a operacionalização de construtos e variáveis e (iv) as técnicas e testes utilizados. Avançando em relação ao realizado por Luft e Shields (2003), além dos estudos em- píricos, os artigos teóricos e teórico-analíticos também foram mapeados.

Um ponto que merece destaque, quanto à identificação das relações causais, é em que trecho da narrativa do estudo estão identificadas as características da relação causal do estudo e se elas foram confirmadas ou não. Nem sempre essas características e confirmação ou não das relações causais são claramente tratadas nos estudos. Nos trabalhos empíricos, as seções de desenvolvimento de hipóteses, testes, discussão de resultados e conclusão são potenciais informantes de tais relações.

No mapeamento, as informações de cada trabalho foram organizadas em tabelas de forma a identificar recorrências, bem como a própria dinâmica temporal das pesquisas em franquias. Nesse mapeamento, as relações não foram separadas por nível de análise, como em Luft e Shields (2003), mas por teoria. No mapa apresentado na Figura $3 \bullet$, as setas indicam causalidade entre variáveis e/ou construtos retirados dos artigos revisados. Variáveis circunscritas em retângulos foram extraídas de trabalhos teóricos-analíticos ou teóricos, enquanto as não circunscritas foram extraídas de artigos empíricos.

Três tipos de relações foram identificadas: aditivas, interativas e moderadoras. As relações aditivas são aquelas nas quais as variáveis explicativas compõem os modelos 


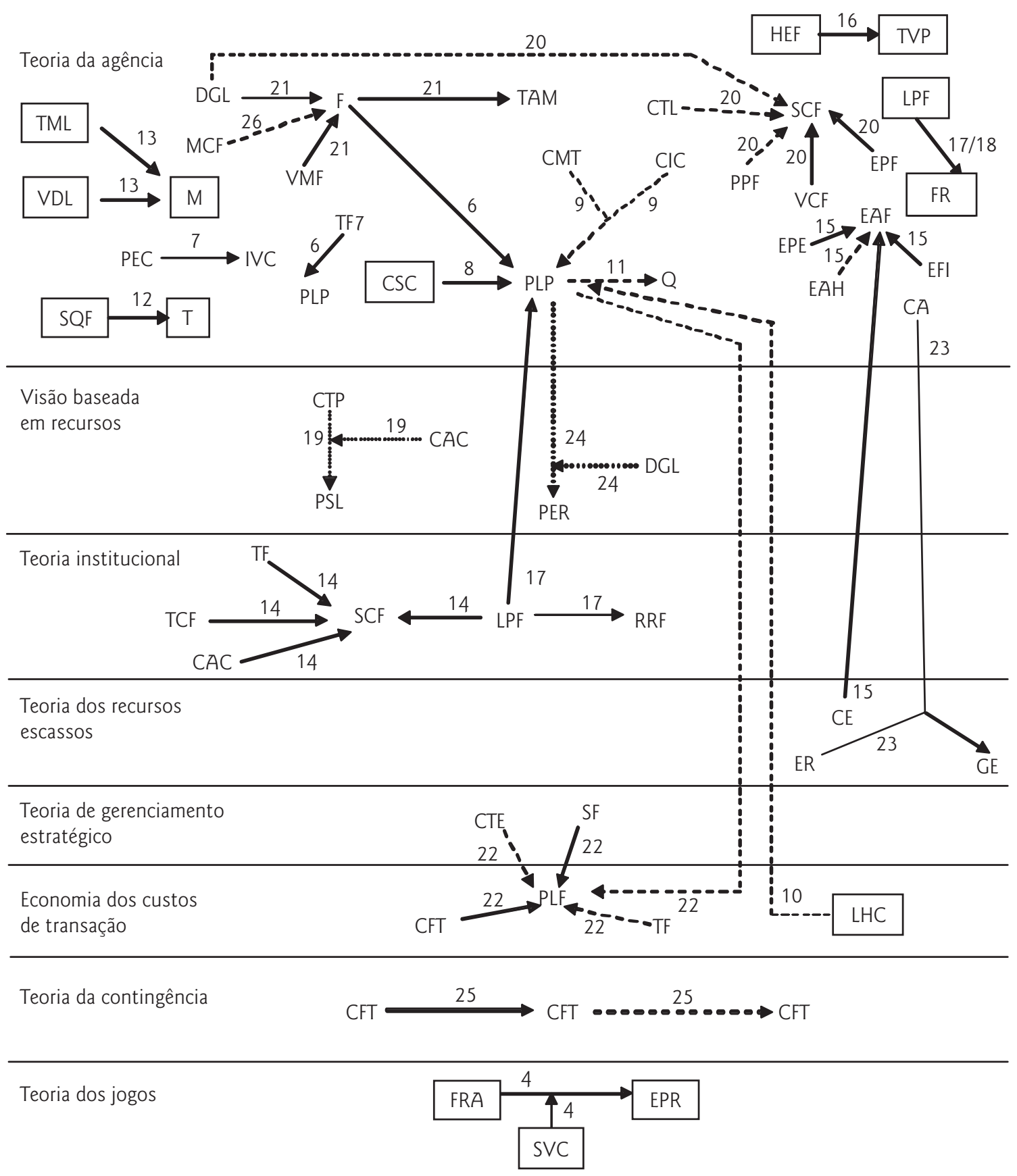

Figura 3 Mapeamento dos estudos sobre franquias no referencial teórico

influenciando as variáveis dependentes, porém com efeitos autônomos, e são representadas por setas simples. Nos modelos interativos, assume-se que duas ou mais variáveis possuem efeitos combinados na explicação do fenômeno. Essas são representadas por setas na forma de " $y$ ". Por fim, o efeito moderador significa que a influência de uma variável só se concretiza na presença de uma segunda variável, efeito esse representado por setas unidas perpendicularmente. Em relação à forma da relação causal, apenas relações lineares foram identificadas. As linhas cheias nas setas indicam relação positiva entre construtos ou variáveis, enquanto as linhas tracejadas representam relações negativas. A forma de representação adotada é a presente em Luft e Shields (2003)

Nas Tabelas 20 e $3 \bullet$, são apresentadas as legendas dos construtos ou variáveis presentes nos estudos empíricos e teórico-analíticos e teóricos, respectivamente. A Tabela 4 traz a correspondência entre o número do estudo e os seus autores.

\subsection{Implicação dos resultados da heurística no desenho de pesquisa}

Como resultado da etapa de elaboração do referencial teórico, considerando a disponibilidade de dados, as restri- 
Tabela 2 Legenda das variáveis presentes nos estudos empíricos

\begin{tabular}{|c|c|}
\hline CA & Custos de agência \\
\hline CAC & Conhecimento acumulado e codificado fornecido pela rede franqueada \\
\hline CAQ & Certificado atestando qualidade (via mídia especializada) \\
\hline CCF & Crescimento da cadeia de franquias \\
\hline CDM & Características demográficas dos mercados \\
\hline CE & Capital escasso \\
\hline CFT & Contratos de franquia tipo "tying" (exclusividade de fornecimento) \\
\hline $\mathrm{CIC}$ & Custos de informação dentro da cadeia \\
\hline CLD & Concorrência local direta no mesmo segmento \\
\hline $\mathrm{CM}$ & Condições mercadológicas (risco, taxa de juros) \\
\hline CMT & Custos de monitoramento das unidades \\
\hline COM & Contigüidade do mercado \\
\hline CTE & Cessão de território exclusivo ao franqueado \\
\hline CTL & Complexidade das tarefas ao nível de loja \\
\hline CTP & Conhecimento tácito do proprietário da loja sobre o mercado local \\
\hline DGL & Distribuição geográfica das lojas próprias \\
\hline EAF & Expansão da rede através da franquia \\
\hline EAH & Especificidade de ativo humano \\
\hline EC & Escassez de recursos \\
\hline ED & Estratégia de diversificação \\
\hline EEF & Efeito específico da cadeia franqueada \\
\hline EF & Efeito específico do franqueado \\
\hline $\mathrm{EFI}$ & Especificidade de ativo físico \\
\hline EMP & Escolha entre franqueados multiproprietários para concessão \\
\hline ENI & Escolha do nível de integração vertical na cadeia de franquia \\
\hline EPE & Expansão para o exterior (EUA) \\
\hline EPF & Experiência prévia do franqueado \\
\hline $\mathrm{F}$ & Franquia como forma organizacional \\
\hline FU & Fechamento de unidades da rede \\
\hline GE & Grupos estratégicos \\
\hline IVC & Integração vertical via cláusulas contratuais \\
\hline LF & Lojas franqueadas \\
\hline LPF & Legislação estatal (proteção de franqueados) \\
\hline MCF & Maturidade da cadeia de franquia (número de lojas e tempo de franquia) \\
\hline MCF & Montante da remuneração de funcionários de lojas \\
\hline $\mathrm{MCL}$ & Montante de capital necessário para abertura de uma loja \\
\hline PEC & Propensão a externalidades na rede \\
\hline PEL & Performance da loja \\
\hline PER & Performance da cadeia \\
\hline PLF & Processos litigiosos dentro da rede de franquia \\
\hline PLP & Proporção de lojas próprias \\
\hline PPF & Propriedade passiva da unidade (master-franquia, gerência regional) \\
\hline PSL & Probabilidade de sobrevivência da uma unidade \\
\hline Q & Qualidade \\
\hline REX & Risco exógeno percebido \\
\hline RRF & Redução da riqueza do franqueador \\
\hline SCF & Sobrevivência da cadeia de franquia \\
\hline SF & Seleção de franqueados experientes no negócio \\
\hline TAM & Tamanho das lojas \\
\hline TCF & Tamanho da cadeia de franquia \\
\hline TF & Tempo de franquia \\
\hline TF & Treinamento de franqueados \\
\hline TF7 & Tempo de franquia (até 7 anos) \\
\hline TFR & Taxa de franquia \\
\hline TRO & Taxa de royalties \\
\hline VCF & Valor para compra de uma franquia \\
\hline VMF & Valor da marca da franquia \\
\hline$\Delta \mathrm{PLP}$ & Alteração percentual no número de lojas próprias da cadeia \\
\hline
\end{tabular}


Tabela 3 || Legenda das variáveis presentes nos estudos teórico-analíticos e teóricos

\begin{tabular}{|l|l|}
\hline CA & Custos de agência \\
\hline CSC & Controle sobre custos \\
\hline FR & Free riding \\
\hline HEF & Heterogeneidade entre franqueados \\
\hline LPF & Legislação de proteção ao franqueado \\
\hline LHC & Limitação da hierarquia corporativa \\
\hline M & Monitoramento de unidades \\
\hline PLP & Proporção de lojas próprias \\
\hline SQF & Sinalização da qualidade da demanda do franqueador \\
\hline TML & Tamanho do mercado da loja \\
\hline T & Taxas \\
\hline TVP & Taxas variáveis de publicidade \\
\hline VDL & Volatilidade da demanda da loja \\
\hline
\end{tabular}

Tabela 4 || Numeração dos artigos representados no mapa

\begin{tabular}{c|l}
\hline 1 & MARTIN, Robert \\
\hline 2 & LAFONATINE, Francine; SHAW, Kathryn L. \\
\hline 3 & KALNINS, Arturs; LAFONATINE, Francine \\
\hline 4 & HADFIELD, Gilian \\
\hline 5 & LAFONATINE, Francine \\
\hline 6 & LAFONATINE, Francine; SHAW, Kathryn L. \\
\hline 7 & BRICKLEY, James A. \\
\hline 8 & MANESS, Robert \\
\hline 9 & NORTON, Seth W. \\
\hline 10 & BROWN (Jr.), Eilliam O. \\
\hline 11 & MICHAEL, Steven C. \\
\hline 12 & DESAI, Preyas S.; SRINIVASAN, Kannan \\
\hline 13 & GAL-OR, Esther \\
\hline 14 & SHANE, Scott; FOO, Maw-Der \\
\hline 15 & COMBS, James G.; KETCHEN Jr., David J. \\
\hline 16 & DESAI, Preyas S. \\
\hline 18 & BRICKLEY, James A.; DARK, Frederick H.; WEISBACH, Michael S. \\
\hline 19 & KLEIN, Benjamin; SAFT, Lester F. \\
\hline 20 & KALNIS, Arturs; MAYER, Kyle J. \\
\hline 21 & SHANE, Scott \\
\hline 22 & NORTON, Seth W. \\
\hline 23 & MICHAEL, Steven C. \\
\hline 24 & CARNEY, Mick; GEDAJLOVIC, Eric \\
\hline 25 & SORENSON, Olav; SORENSEN, Jesper B. \\
\hline 26 & KRUEGER, Alan B. \\
\hline
\end{tabular}

ções de tempo e o nível de maturidade científica atingido, com auxilio do orientador, foi possível desenhar a estratégia final da pesquisa no tema. Optou-se pelo uso da Teoria de Agência. Estudos anteriores desenvolvidos com suporte dessa teoria apresentaram conclusões mais robustas sobre o fenômeno franquias, além de um maior número de hipóteses corroboradas.

Como resultado direto da aplicação da heurística, identificou-se que a ocorrência simultânea entre lojas próprias e franqueadas foi uma variável recorrentemente usada para operacionalizar construtos, tais como a decisão "make- or-buy". Essa operacionalização ocorreu em cinco artigos como variável dependente, sendo inserida no modelo de análise.

O mapeamento de variáveis e a tabulação das características dos artigos trouxeram alguns números interessantes. As relações mapeadas entre variáveis de 19 artigos empíricos levaram à identificação de 199 proxies para captar o efeito dos construtos envolvendo 58 variáveis, derivadas das oito teorias testadas. O método econométrico mais empregado foi a análise de regressão MQO, em 8 trabalhos, seguida da regressão LOGIT, em 6 trabalhos, sendo 
que, em alguns trabalhos, essas duas técnicas são usadas simultaneamente ou em etapas distintas da análise. O uso de variáveis dicotômicas em variáveis independentes ou dependentes ocorreu em 13 trabalhos, indicando alguma fragilidade de mensuração de construtos, mesmo em trabalhos mais recentes.

Na condução da dissertação de mestrado, o conhecimento das variáveis e proxies testadas por outros autores permitiu sugerir construtos não observados previamente. Não foram encontradas pesquisas que mensurassem o efeito da automação de processos de produção sobre a decisão de franquear. Porém, com base na assimetria informacional gerada pela distância entre as diversas unidades de uma cadeia de lojas, foi operacionalizada uma proxy para captar esse efeito, ou seja, buscou-se contribuir para o aprimoramento da pesquisa sobre o fenômeno, tanto por meio da tentativa de testar, no Brasil, as relações teóricas já trabalhadas em estudos anteriores como também por propor refinamentos no desenvolvimento de hipóteses e na operacionalização de variáveis, com o objetivo de contribuir para o desenvolvimento do conhecimento na área.

\subsection{Limitações identificadas no uso da heurística}

O entendimento dos trabalhos revisados esteve limitado ao nível de maturidade científica do mestrando. Em alguns casos, os estudos anteriores faziam referência a conclusões de estudos anteriores, alguns deles não lidos pelo mestrando pela impossibilidade de acesso aos trabaIhos. A maior parte dos artigos permitiu a identificação das relações causais confirmadas nas seções de discussão de testes e resultados. Contudo, em alguns estudos foi identificada inconsistência entre a forma das relações causais propostas, testadas e das justificativas para os resultados. Para triangular a informação sobre a forma da relação causal proposta, compararam-se as diversas seções do texto, com as formas dos testes econométricos. Contudo tal método tem limitações, pois não é capaz de captar se a relação está sendo testada de forma linear por mera simplificação econométrica, ou por ser essa mesma a relação proposta. O mesmo se aplica para relações recursivas cíclicas, que poderiam ser identificadas se declaradas explicitamente pelo autor ou se os testes corroborassem o modelo recursivo.

Refinamentos econométricos, cuja fluência não era possuída pelo mestrando, geraram dificuldades na decodificação, de forma que o entendimento se baseou, na maioria das vezes, nas seções de discussão de resultados e conclusões, e não na própria interpretação dos testes expostos do artigo. A dificuldade foi ainda maior com o estudo de artigos teórico-analíticos, nos quais o mestrando demonstrou dificuldades com o entendimento das modelagens matemáticas. Com o desenvolvimento da pesquisa, parte dessas limitações foi superada nas discussões com o orientador e com outros professores.

\section{CONCLUSÕES}

No presente estudo, argumentou-se que o referencial teórico tem implicações claras na validade interna e a validade de construto de uma pesquisa científica. Assumiu-se que é praticamente impossível alcançar o melhor conjunto de trabalhos científicos para a composição de um referencial teórico, devido à escassez de tempo e recursos e viés pessoal. Ofereceu-se um procedimento que visa a diminuir as perdas na validade interna decorrentes de tais limitações. Argumentou-se que a heurística oferecida permite ao pesquisador alcançar um melhor conjunto possível entre os trabalhos científicos que podem ser utilizados para compor um referencial teórico. Defendeu-se que o uso do processo heurístico aqui proposto pode ajudar o pesquisador a demonstrar mais claramente seus esforços para controlar a introdução de viés que possa comprometer a validade da pesquisa.

Sugeriu-se esse processo para a fase preliminar de estudos empíricos orientados numa visão positiva da pesquisa. A apresentação de critérios explícitos, no protocolo da elaboração do referencial teórico, assegura a replicação da fase de concepção do estudo. Geralmente, a replicação é considerada essencial somente para a parte empírica das pesquisas. Apesar da limitação em dirigir-se apenas a estudos empíricos positivos, o processo pode ser adaptado a outras abordagens de pesquisa, ancoradas nos princípios ontológicos de existência de uma realidade única e de acumulação do conhecimento.

Outra contribuição, comprovada com a aplicação da heurística, foi a de que o pesquisador novato em um tema consegue identificar os pesquisadores de destaque no tópico de pesquisa escolhido, a aceitação da comunidade cientifica com relação a uma ou outra corrente teórica no que diz respeito à explicação do fenômeno, além da área de conhecimento em que cada teoria é mais utilizada, ou seja, há contribuições efetivas ao processo de formação de pesquisadores, uma vez que o entendimento desses aspectos que envolvem a pesquisa científica é essencial para a especialização do pesquisador.

Assim, o processo heurístico apresentado mostrou-se uma ferramenta útil ao desenvolvimento autodidata do pesquisador novato. A aplicação dos procedimentos aqui sugeridos possibilitou um aprofundamento no tópico de franquias, partindo de praticamente nenhum conhecimento anterior sobre o assunto. Observou-se que os resultados obtidos, a partir do processo de mapeamento da pesquisa empírica apresentado por Luft e Shields (2003), puderam ser potencializados pelo processo heurístico de construção de revisão de literatura quanto à seleção de estudos anteriores e à profundidade da análise obtida.

Por fim, o uso rotineiro de protocolos da revisão da literatura com critérios explícitos para a inclusão e exclusão 
dos estudos anteriores, associado com o uso dos processos de mapeamento das relações causais, pode resultar na celeridade da consolidação de teoria e métodos em Contabilidade Gerencial.

\section{Referências}

ABBOTT, A. Methods of discovery: heuristics for the social sciences. London: W. W: Norton \& Company, 2004.

ABERNETHY; M. A. et al. Research in managerial accounting: learning from others' experiences. Accounting and Finance, v. 39, p. 1-27, 1999.

BEATTIE, V. A.; GOODACRE, A. A new method for ranking academic journals in accounting and finance. Accounting and Business Research, v. 36, n. 2, p. 65-91, 2006.

BONNER, S. E. et al. The most influential journals in academic accounting. Accounting, Organizations and Society, v. 31, n. 7, p. 663-685, 2006.

BRUNS, W. J.; KAPLAN, R. S. Accounting and management: field study perspectives. Boston, MA: Harvard Business School Press, 1987.

COVALESKI, M. A. et al. Budgeting research: three theoretical perspectives and criteria for selective integration. Journal of Management Accounting Research, v. 15, n. 3, p. 3-49, 2003

FINK, A. Conducting research literature reviews: from paper to the Internet. London: Sage Publications, 1998.

HART, C. Doing a literature review: releasing the social science research imagination. London: Sage Publications, 1998.

HOPWOOD, A. G. If only there were simple solutions, but there aren't: some reflections on Zimmerman's critique of empirical management accounting research. The European Accounting Review, v. 11, n. 4, p. 777-785, 2002.

KODRZYCKI, Y. K.; YU, P. D. New approaches to ranking economics journals. 2005. Disponível em: <http://www.bos.frb.org/economic/wp/ wp2005/wp0512.pdf>. Acesso em: jan. 2007.

KOZLOWSKI, S. W. J.; KLEIN, K. J. A levels approach to theory and research in organizations. In KLEIN, K. J.; KOZLOWSKI, S. W. J. (Ed.) Multilevel theory, research and methods in organizations. San Francisco: Jossey-Bass, 2000.

LAUGHLIN, R. Empirical research in accounting: alternative approaches and a case for "middle-range" thinking. Accounting, Auditing \& Accountability Journal, v. 8, n. 1, p. 63-87, 1995

LEE, T. A. The editorial gatekeepers of the accounting academy. Accounting, Auditing \& Accountability Journal, v. 10, n. 1, p. 11-30, 1997.

LOWE, A. Perceptions of journal quality and research paradigm: results of a web-based survey of British accounting academics. Accounting, Organizations and Society, v. 30, n. 1, p. 81-98, 2005.

LUFT, J.; SHIELDS, M. D. Zimmerman's contentious conjectures: describing the present and prescribing the future of empirical management accounting research. The European Accounting Review, v. 11, n. 4, p. 795-803, 2002

Mapping management accounting: graphics and guidelines for theory-consistent empirical research. Accounting, Organizations and Society, v. 28, n. 2-3, p. 169-249, 2003.

MARTINS, G. A. Falando sobre teoria e modelo em Ciências Contábeis. Brazilian Business Review, v. 2, n. 2, 2005. Disponível em: <http:/ www.bbronline.com.br/artigos/p/36.pdf>. Acesso em: jul. 2007

REINSTEIN, A; CALDERON, T. G. Examining accounting departments' rankings of the quality of accounting journals. Critical Perspectives on Accounting, v. 17, n. 4, p. 457-490, 2006

SCANDURA, T. A.; WILLIAMS, E. A. Research methodology in management: current practices, trends and implications for future research. Academy of Management Journal, v. 43, n. 6, p. 1248-1264, 2000.

SEARCY, D. L.; MENTZER, J. T. A framework for conducting and evaluating research. Journal of Accounting Literature, v. 22, p. 130-167, 2003. SUTTON, R. I.; STAW, B. M. What theory is not. Administrative Science Quarterly, v. 40, n. 3, p. 371-384, 1995.

TRANFIELD, D.; DENYER, D.; SMART, P. Towards a methodology for developing evidence-informed management knowledge by means of systematic review. British Journal of Management, v. 14, p. 207-222, 2003.

WHETTEN, D. A. What constitutes a theoretical contribution? The Academy of Management Review, v. 14, n. 4, p. 490-495, 1989.

\section{NOTA - Endereço dos autores}

Universidade de São Paulo

Faculdade de Economia, Administração e Contabilidade de Ribeirão Preto

Departamento de Contabilidade

Av. dos Bandeirantes, 3900 - Monte Alegre

Ribeirão Preto - SP

$14040-900$
Fucape Business School

Av. Fernando Ferrari, 1358 - Goiabeiras

Vitória - ES

29075-010 